nan en las escenas el amor profano, salvo en Las Meninas, donde el amor es paternal. Doña Margarita, ya Emperatriz en estas fechas, es para el monarca su «chiquita», como cariñosamente la llamaba ${ }^{46}$.

Debió ofrecer una admirable impresión la visión gris plata y negro, en penumbra y destellos de luz, contrastando con los rojos y dorados ardientes de Rubens y satélites, y los azules y blancos satinados de los maestros italianos, sin olvidar los acordes tenebrosos de las cuatro cabezas de Ribera y el «perfume» de las flores y naturalezas muertas de italianos y flamencos en competición.

Los inventarios no olvidan la decoración de seis bufetes de mármol, con tableros embutidos de jaspe, y siete grandes espejos con molduras de bellos calados en broce y ébano, cuya magnificencia compite - según escribe Bottineau - con los muebles de la sala principal ${ }^{47}$.

Hace unas décadas esta ambientación se revivió en el Museo del Prado, en una estancia consagrada exclusivamente al lienzo de Las Meninas, logrando fingir el intimismo de aquel despacho que implicaba la prolongación del espacio y un encuentro virtual con la Emperatriz.

Matías Díaz Padrón Museo del Prado

\title{
SOBRE LA CORRESPONDENCIA INÉDITA ENTRE JOAN MIRÓ Y SHÛZÔ TAKIGUCHI. RELACIÓN PERSONAL Y COLABORACIÓN ARTÍSTICA ${ }^{1}$
}

Este estudio analiza el intercambio epistolar entre el pintor español y el poeta y crítico japonés Takiguchi por las consecuencias artísticas que ésta tuvo, y porque también de algún modo su relación y colaboración mediatizó la interpretación y aceptación de la obra de Miró entre el público japonés. Se evidencia además cómo el intercambio cultural toca en lo profundo la creatividad artística de ambos, aunque cada uno esté enraizado en su milenaria cultura. Así en las ilustraciones de Miró podemos encontrar trazos caligráficos, y al mismo tiempo contemplar los ojos románicos del Pantócrator.

Shûzô Takiguchi (1903-1979) fue el principal artista japonés implicado en la difusión del Surrealismo en Japón, y el responsable de la introducción de la decalcomanie en su país, proceso pictórico inventado por el español Oscar Domínguez. En Mayo de 1937, en la revista Mizue el pintor Shigeru Imai escribió un artículo titulado «Sobre la Decalcomanía y su méto$d o »$. En este artículo hablaba de la V Exposición de New Plastic Art, y de sus quince decalcomanías a las que acompañaban unos breves poemas de Takiguchi. Imai decía: Así como haiku

\footnotetext{
46 «[...] y la chiquita estuvo a mi lado con gran mesura». Carta del rey a Doña Luisa Enríquez Manrique de Lara, priora del Convento Carmelita de San José, en Malagón, Ciudad Real, Madrid, 11 de abril de 1655, Vid. J. Pérez Villanueva, Felipe IV escritor de cartas. Un epistolario inédito con Velázquez al fondo, Salamanca, 1986, p. 251.

47 Y. BotTineAu, «L'Alcazar de Madrid et l'inventaire de 1686. Aspects de la cour d'Espagne au XVIIème siècle», Op. cit., Bulletin Hispanique, 1958, LX, III, p. 298.

1 Un estudio más desarrollado basado en el intercambio epistolar fue becado y premiado por la Fundació Pilar i Joan Miró de Palma de Mallorca en 1993, por lo que deseo mostrar mi agradecimiento, así como a la Fundació Miró de Barcelona, al Instituto de Japonología, a don Jacques Dupin y al fallecido don Françesc Catalá-Roca, por su amable colaboración.
} 
y haiga (pintura realizada en el espíritu del haiku) estuvieron unidas en nuestro país, ahora poesía y pintura unen también sus manos ${ }^{2}$. Esto hace observar cómo la tradición del arte japonés estaba verdaderamente enraizada en el alma de Takiguchi. El mantuvo este tipo de colaboración con diferentes pintores, entre ellos, dos españoles Antoni Tápies y Joan Miró.

Me gustaría resaltar que fue el único poeta japonés que practicó la «pintura automática», de forma muy próxima a lo que es la esencia del Surrealismo. Tradujo la obra de André Bretón Le surréalisme et la peinture (1930), y mantuvo relaciones con muchos de los surrealistas franceses. Takiguchi puede ser considerado como uno de los líderes de los nuevos movimientos artíticos en Japón. Entre sus pensamientos y actividades cabe destacar su continua preocupación por encontrar la línea común que une la pintura y la escritura. El poeta dijo en el catálogo de su primera Exposición de Dibujo (Octubre, 1960): Todo empezó cuando compré un cuaderno de dibujo. Tracé algunas líneas con una pluma estilográfica. Buscaba algo más que caracteres manuscritos. No sabía si estaba escribiendo o pintando. Lo que me interesaba era esa incertidumbre $^{3}$ (fig. 1).

Coincidiendo con esta etapa su interés por Miró aumenta en relación con la mencionada búsqueda. En 1952 en un ensayo titulado La edad de la abstracción explica sus dudas sobre qué diferencia la escritura del dibujo, y señala: En la antigüedad, las letras estaban muy próximas a las pinturas. Eran casi indistintas. De hecho, algunas estelas antiguas sobre metal o sobre piedra parecen pinturas modernas de Klee o Miró.

En Oriente se desarrolló una forma original de escritura (...), gracias al pincel, a la tinta china, al papel y al clima muy particular, la sensibilidad animista que infunde espíritu a una línea cobra conciencia estética (...) Por otro lado, en la pintura moderna occidental ha aparecido algo muy característico de la escritura oriental ${ }^{4}$. Según el siguiente escrito y los comentarios de Kunio Iwaya, para Shûzô Takiguchi, fueron Klee y Miró, quienes desde la contínua búsqueda pictórica occidental, redujeron la distancia a través de su pintura entre la realidad y los signos, resucitando la vida de las escrituras pictográficas.

Aquí se halla uno de los puntos de contacto entre Miró y el poeta japonés. Takiguchi desde la palabra y Miró desde su pintura caminan en esa cuerda floja que parece ser el límite entre el trazo pictórico y el caligráfico. Probablemente fue este intento de aproximación lo que contínuamente llevó a Miró a colaborar con los poetas en el acompañamiento de sus palabras.

En Mayo de 1958 Shûzô Takiguchi viajó a Italia como miembro del jurado internacional de la Bienal de Venecia representando a Japón. Durante este primer viaje fuera del archipiélago tuvo ocasión de viajar y permaneció en Europa cinco meses. Conoció personalmente a Dalí, Duchamp y Michaux, pero quedó especialmente marcado por su encuentro con André Bretón, llegando a decir que el conocerlo había cambiado su vida. En este tiempo también visitó España y pasó algunos días en casa de Antoni Tápies en Barcelona, sin embargo no tuvo oportunidad de conocer a Joan Miró, que estaba en Palma de Mallorca. Cuando regresó a Japón, tuvo dificultades para continuar su labor como periodista, y se volcó en sus experimentos con la decalcomania.

La gran retrospectiva de Joan Miró en Japón patrocinada por el periódico Mainichi en 1966 favoreció el encuentro personal de estos dos artistas y propició su colaboración en diferentes obras. La relación personal y el intercambio epistolar entre ambos artistas se inicia cuando Shûzô Takiguchi tiene noticia de que Joan Miró viajará a Japón con ocasión de la retrospectiva que iba a celebrarse en Tokyo y en Kyoto, y le escribe una carta que él califica de curieusse

\footnotetext{
2 «Shûzô Takiguchi y la Decalcomanía», Kunio Iwaya. «Sueños de tinta. Decalcomanía de Oscar Domínguez a Marx Ernst». Centro Atlántico de Arte Moderno. Las Palmas de Gran Canaria, 1993, p. 132.

${ }^{3}$ Ibidem, p. 133

${ }^{4}$ Ibidem; p. 135 .
} 
lettre d'identification ${ }^{5}$. En esa autopresentación alude a la monografía que escribió sobre él, y a la noticia que le dio un amigo suyo japonés de haberlo visto en su casa. Le comunica que está participando en la redacción y elaboración del catálogo, y le invita a que le escriba diciéndole aquello que le interesa en lo referente a Japón, por nimio que parezca.

Miró viajó durante la segunda quincena de septiembre y pudo verse con Takiguchi en Tokyo el día 20. Se conserva entre la correspondencia una carta sin datar acompañada del poema manuscrito y mecanografiado Avec des étoiles de Miró, de Septiembre de $1966^{6}$, compuesto en homenaje a Joan Miró con motivo de su retrospectiva. El poeta le pide un dibujo para ilustrar la última estrofa del poema, así como la firma del catálogo de la exposición ${ }^{7}$. No se trata de una carta enviada por el poeta, sino de una nota dejada en el hotel, o entregada durante los días que pasó en Japón ${ }^{8}$.

Se da pues por parte japonesa un primer paso para la colaboración entre ambos artistas. Junto a esta carta y el poema mencionado, adjuntó otro ${ }^{9}$ que había escrito y publicado en 1936 en L'Echange Surréaliste, titulado Joan Miró. Con el tiempo sería incluido en la obra conjunta que realizaron, En compagnie des ètoiles de Miró. Del pintor se conservan unas anotaciones del mes de octubre, al poco tiempo de regresar a España en las que piensa en la posibilidad de realizar un libro escrito en japonés y en francés, «s'en podría fer un llibre preciosista» ${ }^{10}$.

En Mayo de 1967 la Galería Maeght publica Derrière le miroir. Miró. L'Oiseau Solaire L'Oiseau Lunaire - Etincelles, como catálogo de la exposición que de Miró se celebra en la galería. En él incluyen poemas de varios poetas, ilustrados por el pintor, y entre ellos quiso se incluyera Itinéraire, de Shûzô Takiguchi. El artista japonés inmediatamente le agradece en una carta del 7 de Julio su sincera amistad y expresa que siente una gran emoción al ver sus pequeños poemas impresos junto a sus magníficos dibujos. Comenta haber escrito a Adrien Maeght con la idea propuesta por una editorial japonesa de publicar unos dibujos de Miró acompañados de sus poemas en japonés, y quizá también en francés ( $C^{\prime}$ 'est-a-dire, une plaquette composée quelque chose à la japonaise»). Takiguchi pide a Miró que le conceda la oportunidad de llevar a cabo esta idea, fruto de su mutua amistad en el tiempo y en el espacio ${ }^{11}$.

En esta publicación de Derrière le miroir Joan Miró utiliza predominantemente un pincel grueso, suave y redondo, del tipo empleado en la caligrafía. Según el profesor Masao Kameda, los pinceles fueron de las pocas cosas que Miró tenía interés por comprar durante su primer viaje a Japón ${ }^{12}$. Entre las litografías a toda página me gustaría resaltar la primera por la cercanía de lo representado con el ideograma que representa la acción de mirar, $m i(r u)$ 見. En las páginas con texto, de forma salpicada y armónica se entremezclan signos negros medio musicales, medio caligráficos, en los que tan sólo se ha empleado el color de la tinta negra.

En 1968 una nueva publicación, Miró, realizada en colaboración con varios poetas, sale a la luz ilustrada por el pintor catalán, incluyendo de nuevo el poema de Takiguchi, Itinéraire. Los motivos que ilustran el poema son muy sencillos y cercanos a los signos de escritura pictográfica, similitud que resalta aún más al haberse utilizado de nuevo exclusivamente el negro sobre el blanco del papel. En la primera página dos figuras humanas parecen emprender el camino, mientras que en la segunda página, cuatro signos repetidos y salpicados por los márgenes recuerdan el ideograma japonés de origen, comienzo, 元, al tiempo que sugieren una

\footnotetext{
${ }^{5}$ Carta de Shûzô Takiguchi a Joan Miró. Tokyo 14/7/1966. FPIJM, NIG: 6015 Archivo CA039001.

${ }^{6}$ Poema. 9/1966. FPIJM, NIG: 5990.

7 Carta de Shûzô Takiguchi a Joan Miró. Sin datar 1966?. FPIJM, NIG: 5997.

${ }^{8}$ Según comentario carta de Shûzô Takiguchi a Joan Miró. Tokyo 22/7/1969. FPIJM, NIG: 6009 Archivo CA039601.

${ }^{9}$ Poema. 1966. FPIJM, NIG: 5991.

${ }^{10}$ Anotación de Joan Miró. 10/1966. FPIJM, NIG: 5992.

1 Carta de Shûzô Takiguchi a Joan Miró. Tokyo 7/7/1967. FPIJM, NIG:5996.
} 
mayor simplificación de la forma humana, 人. En todas las ilustraciones de los textos se manifiesta la atracción que en ese momento Japón, su sistema de escritura, su caligrafía, sus pinceles y su tinta ejercían sobre él.

Debido a problemas de tipo privado y de salud, Takiguchi guarda un largo silencio epistolar y en Julio de 1969 vuelve a dirigirse a Miró pidiendo disculpas por no haberle escrito ${ }^{13}$. Entre los diferentes proyectos de colaboración que comenta habla de un libro que la editorial barcelonesa Polígrafa le ha propuesto, en el que se recogerían sus poemas ilustrados por Miró, y de aquella publicación de una editorial japonesa, que él deseaba fuera entendida como un homenaje al pintor. Afirma que es su intención que Jacques Dupin elabore los textos en francés con la esperanza de que pueda editarse en ambos idiomas. Takiguchi hace la propuesta de incluir tres de los poemas que compuso como homenaje a Miró, y otros más breves, todavía por escribir, que ilustrados serían semejantes a haikai ${ }^{14}$. Takiguchi le comenta su idea de que el formato del libro que se publicara en Japón siguiera el modelo del tipo acordeón utilizado para los textos budistas.

Se conserva un borrador de la carta de respuesta de Miró en la que le informa de que en noviembre tiene previsto ir a Osaka, y que entonces podrán hablar sobre el tema y fijar el plan de trabajo ${ }^{15}$.

Cuando escribe en agosto ${ }^{16}$, le agradece a Miró que acepte la propuesta de colaborar con él en una obra conjunta. Según indicaciones de la editorial Polígrafa de Barcelona, sería necesario aumentar la cantidad de texto, y por ello Takiguchi le envía a Miró para conocer su opinión dos nuevos poemas que ha escrito Eclair de Terre (6/8/1969) ${ }^{17}$, Rêve Gaudien (8/8/ $1969)^{18}$, y un texto en prosa, Baiser a l'Absolu $(1931)^{19}$, extraído de un escrito publicado en su juventud titulado Experimentations poétiques de Shûzô Takiguchi, 1927-1937. El propio Takiguchi tradujo los textos del japonés al francés y comenta haberlo hecho «literalemente on plutôt dictionnairement». Cuando Miró contesta afirma en su carta ${ }^{20}$ que tiene muchas ganas de hacer algo importante con Takiguchi después de tanto tiempo, pero no considera interesante la sugerencia de la editorial barcelonesa. Su idea es hacer un álbum de lujo con grandes litografías sobre un hermoso papel, y el deseo de Miró es que Takiguchi componga algunas frases poéticas, o que escoja pequeños fragmentos de obras escritas con anterioridad, y que lo haga en caracteres japoneses. Es un hecho que le atraía la concisión de la poesía japonesa pues, en 1967, tras su viaje a Japón, Miró había realizado la ilustración de un libro titulado Haïku (fig. 2), cuyos poemas habían sido traducidos por el poeta Philippe Jaccottet ${ }^{21}$, y entre los fondos de su biblioteca particular se cuenta un libro sobre haiku con una amplia introducción a la obra de los mejores poetas japoneses ${ }^{22}$.

\footnotetext{
${ }^{12}$ Entrevista Nara (Japón) 6/1993. El profesor Masao Kameda era reportero del periódico Mainichi de la zona de Kansai cuando Joan Miró viajó a Kyoto, y estuvo entre las personas que le acompañaron durante su estancia allí.

${ }^{13}$ Carta de Shûzô Takiguchi a Joan Miró. Tokyo 22/7/1969. FPIJM, NIG: 6009, Archivo CA039601.

${ }^{14}$ Haikai: se denomina así de una manera general a todo lo que rodea la composición del haiku, aunque en ocasiones se ve empleado como sinónimo de haiku, siendo éste un poema de 5/7/5 sílabas que contiene en su brevedad una gran emoción y un enorme poder de evocación.

${ }^{15}$ Carta borrador de Joan Miró a Shûzô Takiguchi. Palma de Mallorca, 15/8/1969. FPIJM, NIG: 6008, Archivo CA039801.

${ }^{16}$ Carta de Shûzô Takiguchi a Joan Miró. Tokyo 30/8/1969. FPIJM, NIG: 5998 Archivo CA039701.

17 Poema enviado junto carta de 30/8/1969. FPIJM, NIG 5999 Archivo CA039701.

18 Poema enviado junto carta de 30/8/1969. FPIJM, NIG 6000.

${ }_{19}$ Poema enviado junto carta de 30/8/1969. FPIJM, NIG 6001

${ }^{20}$ Carta borrador. de Joan Miró a Shûzô Takiguchi. 28/9/1969. NIG 6006 Archivo CA039901.

${ }^{21}$ Según entrevista Jacques Dupin, este poeta desconocía el idioma japonés (Madrid 12/4/1996). En el libro no consta de qué idioma u obra fueron sacados y traducidos los poemas.

${ }_{22}$ Bonneau, Georges: Le Haiku. Tomo 9, Le Colleccion Yoshino. Librairie Orientaliste Paul Geuthner. Paris, 1935.
} 

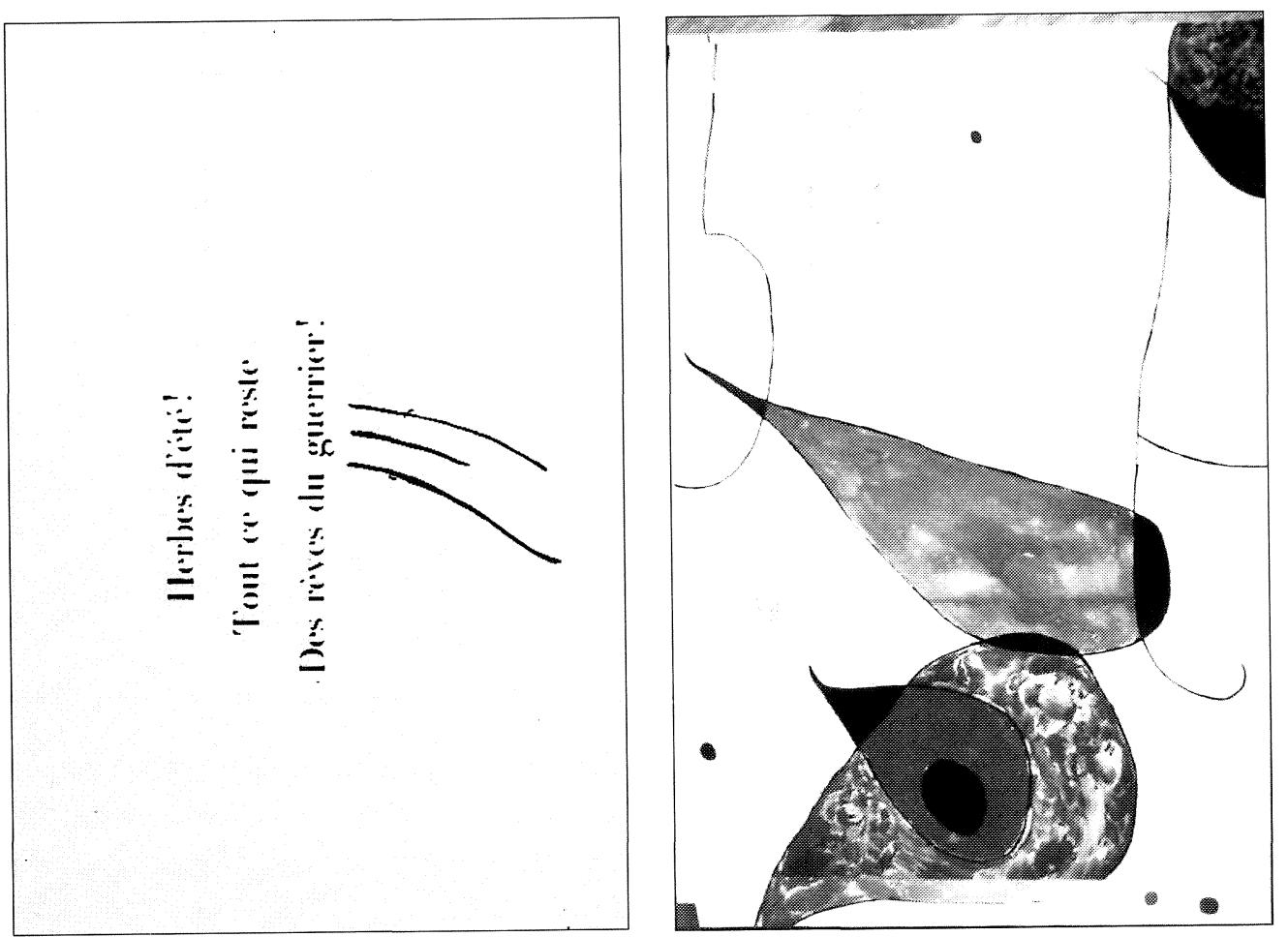

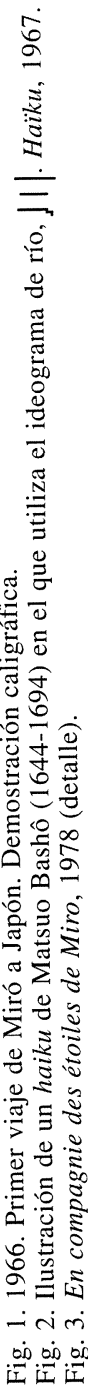

N

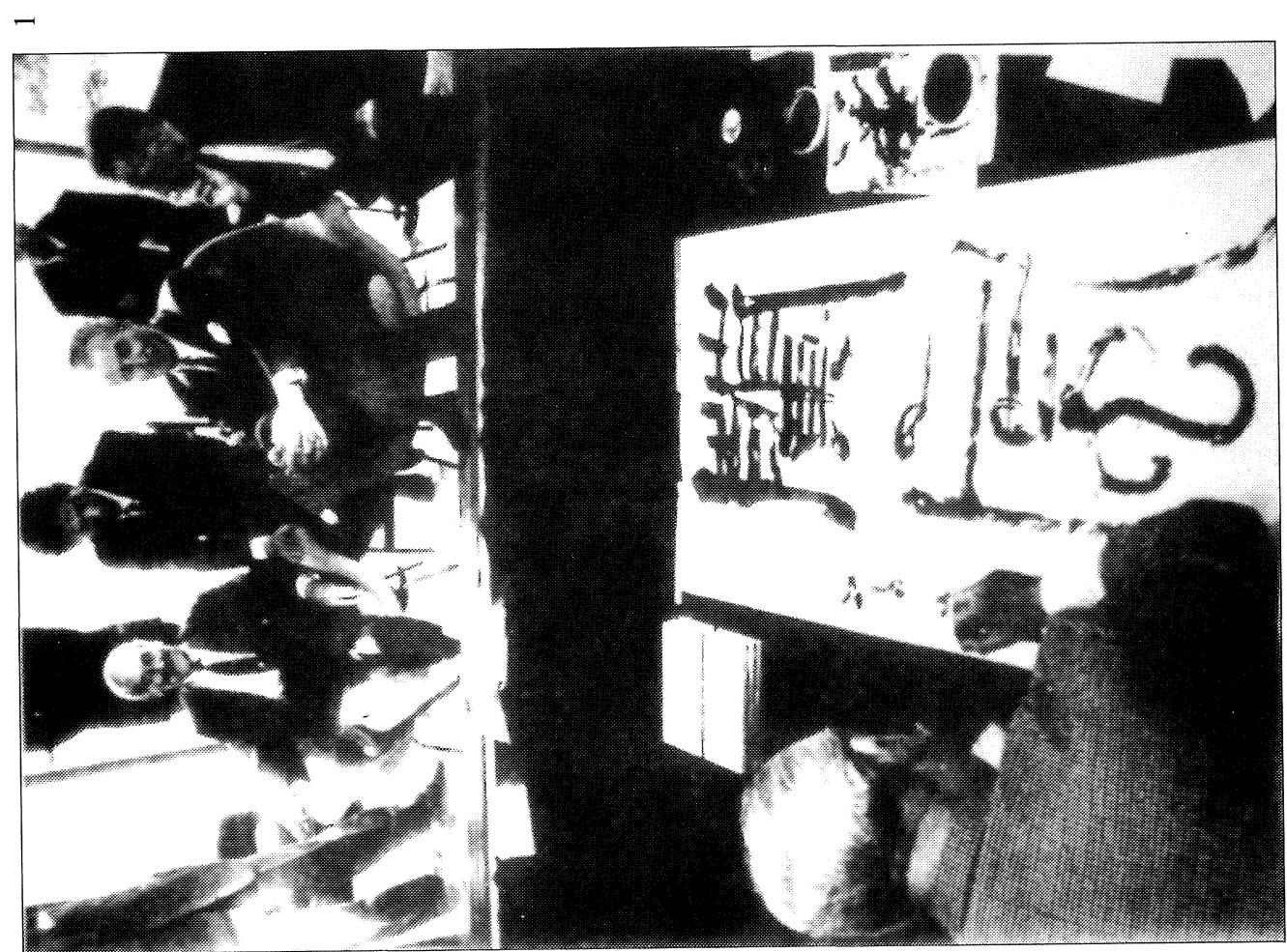


Sentía fuertemente que pintura y poesía estaban estrechamente ligadas, y en estas pequeñas poesías encontraba concentrada toda la emoción que la palabra puede evocar. Intentaba que sus dibujos, a modo de haiga ${ }^{23}$, respondieran a la emoción poética despertada por los versos. En esta ocasión desea ilustrar los poemas de Takiguchi inspirándose en los grafismos de su escritura. La idea de Miró era que no hacía falta sobrecargar el álbum con demasiados textos, y confiesa imaginarlo ligero y precioso como una flor. Esta fue la línea de su primera obra en colaboración.

Cuando Miró llega a Japón en noviembre de 1969 para su trabajo en el Pabellón de Osaka Gas, en su carta de bienvenida ${ }^{24}$ Takiguchi le comenta que ya ha escrito el texto para el álbum: 15 poemas muy cortos y simples, algunos de los cuales están muy cerca del haiku, sobre todo los proverbios, y añade que podrían titularse Proverbes à la main.

Quisiera llamar la atención sobre este fenómeno que se repite en muy difentes campos, en el arte, la política, la sociedad, etc., y que es la valoración occidental de lo japonés, que hace a Japón mirarse y redescubrirse. Miró, invita a Takiguchi a olvidarse de los modernos escritos en prosa surrealista, para concentrarse en la creación de pequeños y condensados poemas, ricos en evocación, semejantes a los haiku.

Contemplando la obra final, el espectador descubre la verdadera compenetración lograda entre ambos artistas. La composición recuerda por su verticalidad y la diagonalidad la manera de distribuir las masas el modo de hacer típicamente japonés. Se acentúa este sabor con la monocromía de la tinta y el formato alargado del total de los poemas. Se aprecia una tendencia a elevarse en las distintas composiciones, con un movimiento ascendente que invita a escapar del papel. En la versión japonesa se diluye la importancia del dibujo ante la presencia de los signos pictográficos: el mayor grosor en las líneas negras de la tipografía y la mayor cantidad de trazos de los ideogramas, así como el título y el nombre del poeta en letras más grandes, evidencian que Miró valoró aquellos signos al elaborar su obra. En esta versión el peso del título y del nombre del autor, cortan el movimiento ascendente de la composición, que a diferencia de lo que ocurre en las otras versiones del poema, se retiene al lector.

Por otra parte quisiera resaltar cómo en Proverbes à la main Miró ablanda y engrosa la pincelada, recordando de nuevo el trazo caligráfico. En esta obra su aproximación a Japón es aún más evidente que en aquellas otras en las que la presencia de Takiguchi se entremezclaba con la de otros poetas, y lo es aún más sabiendo que fue él quien eligió este tipo de poemas breves.

Cuando Shûzô Takiguchi recibió Proverbes à la main, no pudo más que asombrarse del efecto tan sumamente japonés conseguido en esta obra, diciendo que constituía un monumento a su amistad, y también a la amistad de Miró y Japón ${ }^{25}$. El poeta describe la aportación de Miró diciendo que cada página de texto está admirablemente acompañada de un gran dibujo caligráfico de gran simplicidad e intensidad, y alude a su formato diciendo que está muy cerca del kakemono ${ }^{26}$ japonés. Añade en esta carta que le ha enviado por correo papel japonés, y que de un modo atrevido espera que acepte escribir el título de la obra Proverbes à la main a tinta china y pincel, con su propia calligraphie-dessin-écriture, para colgarlo en su habitación como si de un kakemono se tratara, pensando además en prestarlo para la proyectada exposición de la obra en la Galería Minami de Tokyo. Esta admiración por la caligrafía de Miró y su juego entre la escritura y el dibujo, evidencia lo cercano que sentía Takiguchi a Miró de la tradición japonesa.

\footnotetext{
${ }^{23}$ Haiga: pintura que ilustra la emoción poética de un haiku.

${ }^{24}$ Carta sin datar de Shûzô Takiguchi a Joan Miró. Tokyo?, ?/11/1969. FPIJM NIG: 6013 Archivo CA040801.

${ }^{25}$ Carta de Shûzô Takiguchi a Joan Miró. Tokyo 7/6/1970. FPIJM. NIG: 6003 Archivo CA040301.

${ }^{26}$ Kakemono: formato pictórico desarrollado en vertical, pensado especialmente para ser colgado sobre el tokonoma o lugar principal de la casa japonesa.
} 
La Galería Minami de Tokyo, organizó la mencionada exposición y Shûzô Takiguchi en una carta le comenta a Miró cómo dicha exposición ha provocado una gran impresión entre los jóvenes, quienes se mostraban muy interesados por su obra ${ }^{27}$. En esa misma carta lamenta que su enfermedad, y problemas de edición, estén retardando tanto aquella otra que quería dedicarle, y que será En compagnie des étoiles de Miró. Fue un trabajo dificil de elaborar y editar, y no vio la luz hasta 1978, casi diez años después de que surgiera la idea, debido en parte a que el libro en principio iba a ser publicado como una edición privada ${ }^{28}$. El pintor en sus cartas se refería a él como «un trabajo importante» ${ }^{29}$.

En el prólogo el poeta comenta con gran sinceridad la fuerte experiencia que para él supuso poder pasar tres días con Miró, poco antes de que regresara, y una vez finalizados sus trabajos en el Pabellón de Osaka Gas. Takiguchi manifiesta que fue entonces cuando, queriendo retener la intensidad de lo que estaba viviendo, escribió a vuela pluma Raison de rire, el último de los poemas recogidos en En compagnie des étoiles de Miró.

Realmente esta obra podría definirse como la culminación de esa relación y mutua admiración cultivada con el paso de los años. En ella puede contemplarse lo más característico de la obra de Miró, y al tiempo los sentimientos más profundos que despertaba en Takiguchi, pudiendo quizás hacer extensivo el sentimiento del poeta al de miles de espectadores de la obra del pintor catalán.

El formato en esta ocasión como comenta en su carta, fue sugerido por Takiguchi, quien siempre quiso que la obra tuviera el formato plegado de los sutras budistas. Quizás en esta muestra de admiración deseaba que la consideración sagrada de los textos caligrafiados en este formato impregnara también su obra homenaje a Miró. Este formato despertó el entusiasmo del pintor, pues le ofrecía unas posibilidades diferentes para el desarrollo del discurso, y le permitía integrar sus propios signos con la tradición de la escritura japonesa ${ }^{30}$. La fusión de ambos lenguajes ofrece al espectador una obra para deleitarse con el juego de formas, equilibrios y armonías, más allá de las adivinanzas de significados ${ }^{31,32}$ (fig. 3).

\footnotetext{
${ }^{27}$ Carta de Shûzô Takiguchi a Joan Miró. Tokyo 5/2/1971. FPIJM. NIG: 6014 Archivo CA040401.

${ }^{28}$ El título definitivo de esta creación conjunta fue En compagnie des étoiles de Miró (Miró no hoshi totomo ni). Finalmente su publicación corrió a cargo de la editorial japonesa Heibonsha, aunque la impresión de la litografía fue realizada en París por Arte Adrien Maeght. Takiguchi en su carta de Mayo de 1977 afirma que la editorial está ilusionada por esta edición que resulta rara y excepcional en Japón. Carta de Shûzô Takiguchi a Joan Miró 29/5/1977. FPIJM. NIG 6016 CA 0040701 .

${ }^{29}$ «juyô na shigoto», Shûzô Takiguchi, prólogo de En compagnie des étoiles de Miró. Carta borrador de Joan Miró a Shûzô Takiguchi 28/9/1969. NIG 6006 CA 039901.

Shûzô Takiguchi escribió para la obra un prólogo en japonés en un estilo sumamente formal. En él manifestó que realmente En compagnie des étoiles de Miró fue el fruto de la colaboración de un buen número de personas que se vieron implicados en su elaboración. El poeta hace hincapié en la enorme dificultad que ha supuesto este trabajo en colaboración con un artista extranjero. Debemos imaginar tras sus palabras obstáculos tales como la distancia con el tiempo empleado en esperar constestaciones, la imposibilidad de verse en persona, la enfermedad y debilidad de Takiguchi que le impedía viajar, el idioma, el modo de trabajo de los occidentales, etc.. Agradece de forma expresa a Joan Miró su gran interés y preocupación por la realización de este «trabajo importante», tal y como lo llama el pintor en sus cartas, y también su amistad. Concluye el prólogo diciendo que en este ochenta y cinco aniversario del nacimiento de Miró, desde Japón desean presentarle la obra como regalo.

30 Visualmente ofrece un aspecto más liviano que el chino al utilizar en su discurso ideogramas simplificados para desinencias, preposiciones y partículas.

${ }^{31}$ En compagnie des étoiles de Miró fue publicada exclusivamente en japonés, si bien se añadió una pequeña separata ilustrada en tonos grises con la traducción de los poemas al francés. En sus páginas se menciona que la traducción al francés es obra de Takiguchi, supervisada por Jacques Dupin, y Takiguchi en el prólogo así lo reconoce y le agradece su colaboración. Sin embargo, Dupin en la entrevista del 18/4/1996, creía recordar que siempre había hablado con él en inglés, y se sorprendía al saber que las cartas dirigidas a Miró las había escrito en francés, e incluso pensaba en la posibilidad de que alguien lo hubiera hecho por él.

${ }^{32}$ En ella se aprecia cómo el pintor se dejó penetrar por el sentido del texto y lo tradujo en imágenes plásticas propias de su vocabulario. El dibujo y el color se hace más abundante conforme discurre la obra y aumenta el volumen de texto. El último poema, que es más denso en escritura, está acompañado, no de líneas como ocurre en los primeros, sino de grandes
} 
Contrasta la portada llena de color presidida por su estrella, con la contraportada, en la que destacan los trazos negros sobre el blanco del papel, siendo una pequeña intersección azul la única mancha de color que llama nuestra atención y retiene la mirada. Transmite la impresión de ser una conclusión serena de la obra. Este elaborado gran tesoro artístico fue presentado junto con una litografía suelta, cuidadosamente envuelto en papel japonés en una caja lacada, acentuando aún más su sabor japonés ${ }^{33}$.

A través del seguimiento de la correspondencia entre Miró y Takiguchi, se pone de manifiesto que gran parte del valor de estas obras realizadas en colaboración es fruto del enriquecimiento derivado de la interacción cultural. El poeta ejemplifica la admiración japonesa por el mundo del arte contemporáneo en Occidente, y el pintor la aceptación de lo japonés como válido en el camino del arte contemporáneo occidental.

Pilar Cabañas Moreno

\section{EL ESCULTOR JUAN FERNÁNDEZ Y SU DESCONOCIDA OBRA EN TOLEDO}

En la Capilla del Sagrario de la Catedral de Toledo, situados a gran altura en unos nichos del muro del mediodía, se sitúan dos grandes esculturas de San Pedro y San Pablo que llaman la atención por su magnífica apostura. Las guías más conocidas que describen la capilla ${ }^{1}$ las identifican como obras en bronce del escultor Juan Fernández.

Parecía extraño que obras de esa envergadura hubieran pasado desapercibidas a los estudiosos de la escultura aunque su dificil accesibilidad lo justificaba. En realidad por lo que podía apreciarse desde abajo y las noticias sobre su material aconsejaron su estudio pausado más teniendo en cuenta que Pompeyo Leoni, el gran maestro de la obra en bronce de los Entierros del Escorial, tuvo un encargo de la catedral de Toledo.

Desmontadas hace poco se supo que las esculturas eran en realidad de madera y que hubo de sanearse la madera atacada por polilla que no había evitado la rica capa de panes de oro que la recubrían ${ }^{2}$. La noticia planteaba el problema de saber cómo se había divulgado el error

formas coloreadas, concluyendo la obra con una gran mancha roja para equilibrar la pesadez visual del texto, contrapunto de aquel círculo rojo pequeño que aparecía al inicio como recuerdo del símbolo de Japón, el sol naciente. Se entiende porqué, aunque sólo fuera por razones ópticas y estéticas, Miró rechazara la idea de incluir prosa en Proverbes à la main. La abundancia de ideogramas emborracha. No es de extrañar que finalmente no se hiciera en otro idioma, ya que hubiera sido una obra totalmente diferente. El hermoso juego entre la verticalidad de las líneas de escritura y la horizontalidad del discurso pictórico, hubiera sido difícil de lograr con el sistema de escritura occidental. La forma de escribir de arriba hacia abajo, y de derecha a izquierda, permite la utilización de un formato que ayuda a leer el discurso escrito y el pictórico de forma continuada, dejándonos avanzar sin llegar al final «de página», hasta que la obra concluye. Ritmo y equilibrio son dos de las características que mejor definen esta obra.

${ }^{33}$ Los poemas recogidos en esta obra son: Joan Miró (1936); En compagnie des étoiles de Miró (1966); Itinéraire (1967) y Raison de rire (1969).

' PARro, Sixto-Ramón, Toledo en la mano o descripción histórico-artística de la magnífica catedral y de los demás célebres monumentos. Toledo, 1857. Edición del Instituto Provincial de Investigaciones y Estudios toledanos, 1978. CEDILLo, Conde de, Catálogo Monumental y Artístico de la Catedral de Toledo. Toledo, 1919. Edición con introducción y notas de Matilde Revuelta. Diputación Provincial de Toledo, 1991. Inventario artístico de Toledo.Tomo II, La Catedral Primada (Vol. I), 1989.

${ }^{2}$ Agradezco la inapreciable ayuda de D. ${ }^{a}$ Matilde Revuelta que me facilitó el informe del restaurador Don Luciano Gutiérrez Gómez confirmando que su madera habia sido atacada por la polilla.También a Don Evencio Cófreces, Deán de la Catedral, su autorización para que se les hicieran fotografías, dificiles de realizar por la altura en la que se encuentran. 